\title{
Review
}

Neuropsychobiology

Neuropsychobiology 2015;72:195-205

DOI: $10.1159 / 000439384$
Received: January 26, 2015

Accepted after revision: August 11, 2015

Published online: February 23, 2016

\section{Assessment of Wakefulness and Brain Arousal Regulation in Psychiatric Research}

\author{
Christian Sander Tilman Hensch Dirk Alexander Wittekind Daniel Böttger \\ Ulrich Hegerl \\ Department of Psychiatry and Psychotherapy, University Hospital Leipzig, Leipzig, Germany
}

\section{Key Words}

Sleep-wake regulation - Wakefulness - Brain arousal .

Two-process model · Electroencephalography · Vigilance .

Vigilance Algorithm Leipzig · Depression · Mania · Affective disorders $\cdot$ Treatment response prediction

\begin{abstract}
During the last few decades, much knowledge has been gained about sleep being a heterogeneous condition with several distinct sleep stages that represent fundamentally different physiological states. The same applies for the wake state which also comprises distinct global functional states (called vigilance stages). However, various terms and concepts have been introduced describing different aspects of wakefulness, and accordingly several methods of assessment exist, e.g. sleep laboratory assessments (Multiple Sleep Latency Test, Maintenance of Wakefulness Test), questionnaires (Epworth Sleepiness Scale, Karolinska Sleepiness Scale), behavioural tasks (Psychomotor Vigilance Test) or electroencephalography (EEG)-based assessments (Alpha Attenuation Test, Karolinska Drowsiness Test). Furthermore, several theoretical concepts about the regulation of sleep and wakefulness have been put forward, and physiological correlates have been identified. Most relevant for healthy functioning is the regulation of brain arousal and the adap-
\end{abstract}

tion of wakefulness to the environmental and situational needs so that the optimal balance between energy conservation and responsiveness can be obtained. Since one approach to the assessment of brain arousal regulation is the classification of EEG vigilance stages, a computer-based algorithm (Vigilance Algorithm Leipzig) has been introduced, allowing classification of EEG vigilance stages in EEG recordings under resting conditions. The time course of EEG vigilance stages in EEGs of 15-20 min duration allows estimation of the individual arousal regulation (hyperstable, adaptive, or unstable vigilance pattern). The vigilance model of affective disorders and attention-deficit/hyperactivity disorder links a disturbed arousal regulation to the pathogenesis of psychiatric disorders and accordingly helps to explain and possibly also predict treatment effects of pharmacological and nonpharmacological interventions for these conditions.

(c) 2016 S. Karger AG, Basel

\section{Beyond Sleep Disorders - Importance of Wakefulness Regulation}

Sleep disturbances are a common complaint in psychiatric disorders, particularly in affective disorders. In depression, a pathological sleep pattern with prolonged sleep latencies, disturbed sleep continuity and early

\section{KARGER 125}

(c) 2016 S. Karger AG, Base

0302-282X/16/0724-0195\$39.50/0

E-Mail karger@karger.com

www.karger.com/nps
Christian Sander

Department of Psychiatry and Psychotherapy, University Hospital Leipzig Semmelweisstrasse 10 DE-04103 Leipzig (Germany)

E-Mail publications@ipeg-society.org 
awakenings is often seen, paralleled by an altered sleep architecture with decreased slow-wave sleep and increased rapid-eye-movement density in the first sleep cycle [1]. Believed to be merely a symptom of depression in the past, more recent evidence suggests a central role for disrupted sleep in the pathophysiology of depression [2]. It has been observed that sleep duration can influence mood: especially in patients with bipolar affective disorders, oversleeping leads to worsened mood while shortened sleep duration has mood-enhancing and sometimes even promanic properties [3, 4]. This paradox effect is further illustrated by the effectiveness of sleep deprivation therapy in unipolar and bipolar affective disorders, which quickly amend depressive symptomatology [5] until the next sleep is initiated. Often, depressed patients subjectively interpret their symptoms as a sign of tiredness and try to ameliorate them by seeking additional rest and sleep. However, inactivity in most cases negatively impacts mood, and some evidence exists suggesting that on the contrary behavioural activation and chronically restricting bed times might improve mood and depressive symptoms $[6,7]$.

Although sleep problems are a main burden of depressed patients, it would be unjustified to focus on their sleep alone, as the wake state comprises the largest part of the day. Still, terminological discrepancies and methodological pitfalls have led to a predominance of sleep-related research. Within the last centuries, sleep has been well described as a non-homogeneous state with several distinct sleep stages that can reliably be separated using objective electroencephalography (EEG)-based measurements. The wake state has often been described as 'not sleeping' and was not considered further. However, the wake state can also be subdivided into several substages which, just like the sleep stages, can best be classified based on specific EEG features (see below). This knowledge exists since the 1960s, when these substages were first described $[8,9]$; however, this has received much less attention compared to the sleep stages.

One reason for the lesser acknowledgement of the wake stage differentiation within the research community might be that levels of wakefulness have been conceptualized independently within several research fields with specific focus, be it psychophysiology, psychology or cognitive neuroscience. Therefore, several terms and concepts have been put forward, which are in parts synonymous, contradictory or simply referring to specific aspects of wakefulness, like arousal, alertness or vigilance. Arousal can be defined as the state of physiological activation, and a generalized central nervous system or brain arousal is considered to underlie all motivated behaviour [10]. Alertness describes a state of responsiveness and watchfulness to mostly external stimuli. The term vigilance has been used with differing meanings, too [11]: originally coined to describe a state of maximal physiological efficiency [12], during which an organism is most receptive for information, the term is frequently used to describe the ability to maintain attention and alertness over long durations and has become a synonym for sustained attention in psychology. It is also used to describe the arousal level on the spectrum from sleep to wakefulness, especially to describe different states of wakefulness (vigilance levels, see below). Furthermore, several terms have been coined to describe states of reduced wakefulness (but not sleep), such as sleepiness (describing either the biological need for sleep or the subjective feeling of being in need of sleep [13]), drowsiness (a state of impaired awareness associated with a desire to sleep as concomitant phenomenon to e.g. following drug administration), tiredness (a general loss of energy resulting in most cases from physical or mental effort) or fatigue (a more specific form of tiredness, describing e.g. performance decrement after prolonged activity and physical effort or - in a clinical context - exhaustion and energy loss accompanying several chronic diseases). Accordingly, for each concept, specific assessments have been put forward (see the section Assessment of Wakefulness).

The specific function and importance of sleep for a healthy life and optimal functioning of an organism is still not fully understood. Likewise, the role of a disturbed sleep regulation and the impact of sleep disorders on overall health, well-being and functioning remain a hot research topic. However, the importance of a well-working wakefulness regulation cannot be underestimated. Life is constant interaction with the environment, and each organism needs to adapt to the environmental needs and challenges. On the one hand, it is important to adapt one's own degree of wakefulness to the specific needs and challenges of the current environment to achieve goals and avoid harm and potential death (e.g. avoiding or coping with dangerous situations); on the other hand, it is important to actively shape or seek an environment fitting to the current amount of wakefulness (e.g. find a safe place to sleep). Accordingly, if the regulation of brain arousal is disturbed or even worse chronically altered, health, functioning and well-being are severely threatened. 


\section{Neurobiology of Sleep and Wakefulness}

The most influential model on sleep-wake regulation has been the two-process model of sleep regulation [14, 15]. According to this model, the timing of sleep and wakefulness is the result of two interacting processes, a circadian process $\mathrm{C}$ and a homeostatic process $\mathrm{S}$. The homeostatic process $S$ is said to rise during wakefulness resulting in a growing sleep propensity, and to degrade exponentially during sleep. The circadian process $\mathrm{C}$ is considered to rise and decline in a periodical manner, which has been shown to follow an about 24-hour cycle, and is considered to modulate two thresholds $\mathrm{H}$ and L. Sleep onset should occur if during wakefulness, the growing process $S$ reaches threshold $\mathrm{H}$, whereas wake sets in after the degrading process $S$ has reached threshold L during sleep. Inspired by the two-process model, a three-process model of alertness and sleepiness has been formulated [16-18]: in this mathematical model, process $\mathrm{C}$ describes sleepiness due to circadian influences and process $S$ is an exponential function of time since awaking which is declining during wakefulness and exponentially rises during sleep. The time course of daytime alertness was simulated by complementing the interaction between processes $\mathrm{S}$ and $\mathrm{C}$ with a third component - process $\mathrm{W}$ or sleep inertia after waking. Inertia components (at the transition points from wake to sleep and sleep to wakefulness) have since then also been applied to the original two-process model to simulate daytime vigilance, alertness and sleepiness [19].

Furthermore, it has been suggested that solely focussing on a sleep-promoting drive is not sufficient to explain many phenomena surrounding sleep-wake regulation. Thus, a four-process model of sleep and wakefulness has been introduced [20], which postulates two mutually inhibiting drives: the sleep drive and an antagonizing wake drive. Whether a subject is asleep or awake is said to depend on the preponderance of the relative strength of the two drives, not the absolute strength of one. Both drives result from the additive effects of a primary and a secondary component, the primary one being derived from activity of neuronal groups and the secondary influenced by homeostatic aspects or behaviour (i.e. the secondary sleep drive corresponds to process $S$ of the two-process model).

Much knowledge has been gained about the physiological correlates of the described theoretical processes [for reviews, see 21-24]. There is not one brain structure or region that is responsible for the regulation of sleep and wakefulness but several regions; almost all transmitter systems and a multitude of other neuropeptides are linked in a highly complex regulatory system. In general, there are several

Wakefulness and Brain Arousal Regulation in Psychiatric Research arousal-promoting brain centres which are highly active during wakefulness and activate the cortex. These incorporate cholinergic, noradrenergic, serotonergic, dopaminergic and histaminergic nuclei in the brain stem, the posterior hypothalamus, the basal forebrain and the relay nuclei of the thalamus. Counterparts to these arousal-promoting regions are sleep-promoting regions such as the ventrolateral pre-optic area and the median pre-optic nucleus of the pre-optic area of the hypothalamus. There are extensive connections between all these brain centres with arousalpromoting regions activating other arousal-promoting regions while inhibiting sleep-promoting areas and vice versa. Due to the mutual inhibition, the metaphor of a flip-flop switch has been proposed [24], which is switched either to sleep or wakefulness and corresponds well with the primary sleep and wake drives from the four-process model.

As predicted in the theoretical models, there are circadian and homeostatic influences on the components of the flip-flop switch. One potential physiological equivalent to the homeostatic process $S$ has been identified in the neuromodulator adenosine, a rundown product of cellular metabolism, which is accumulated extracellularly in the basal forebrain during wakefulness and is decomposed during sleep [25]. Applications of adenosine agonists into specific brain regions cause sleep, and drugs like caffeine cause their wake-promoting effect by blocking adenosine receptors. Concerning process $\mathrm{C}$, the suprachiasmatic nucleus ( $\mathrm{SCN}$ ) has been identified as the main generator of circadian rhythms, although peripheral pacemakers exist in almost every organ and tissue. Still, the SCN serves as a master clock and adjusts all circadian rhythms to an about 24-hour rhythm which is generated by feedback loops in the expression of clock genes. The SCN rhythm is entraining to the day-night cycle as light-dark information reaches the SCN via photosensitive retinal ganglion cells. However, the SCN has relatively little direct connections to either sleep or wake centres. Circadian information is transmitted by the subparaventricular zone and from there to the dorsomedial nucleus of the hypothalamus which innervates the ventrolateral pre-optic area (sleep-promoting area) and the lateral hypothalamic area (wakefulness-promoting area). This allows the sleep-wake rhythm to be coordinated with other biological rhythms and needs.

\section{Assessment of Wakefulness}

There are several available means to assess wakefulness [for reviews, see 13,26], most of them covering specific aspects. Most easily applied are questionnaires such 
as the Epworth Sleepiness Scale [27], the Stanford Sleepiness Scale [28] or the Karolinska Sleepiness Scale [29]. With the Epworth Sleepiness Scale, a subject is requested to rate the likelihood of falling asleep within 8 given situations, therefore the scale quantifies the overall amount of sleepiness and its impact on functioning within a certain period of time. Clinically, the questionnaire is mostly used as a screening instrument for excessive daytime sleepiness but cannot be used to assess the acute level of sleepiness and even less changes in wakefulness within short intervals. For these purposes, the Stanford and Karolinska Sleepiness Scales were developed which are short rating scales on which a subject is asked to rate its current level of wakefulness. This can be repeated frequently; however, answers reflect the subjective estimation of the subject which can differ from the physiological sleep propensity or level of wakefulness.

Therefore, objective assessments have been developed, the most widely used being the Multiple Sleep Latency Test (MSLT) [30] and the Maintenance of Wakefulness Test (MWT) [31]. Both are to be performed in a sleep laboratory, require a polysomnography set-up and have comparable implementation conditions (e.g. several trials repeated every $2 \mathrm{~h}$ ). Still, they assess different aspects: the MSLT measures the propensity of falling asleep whereas the MWT measures the ability to resist falling asleep, two skills that are not necessarily associated [32]. Within the MSLT, subjects are placed in a comfortable position (lying in bed in a dark and quiet room) and are instructed to try to fall asleep. It is recorded whether or not they do so within a 15-min trial and after what amount of time (sleep onset latency). Normally, 4-5 trials are performed every $2 \mathrm{~h}$. An average sleep onset latency of $10 \mathrm{~min}$ and more is considered as normal sleepiness while an average sleep onset latency of $5 \mathrm{~min}$ or less is interpreted as abnormal sleepiness. Due to its set-up and instruction, the MSLT cannot be used to assess the ability to stay awake, which may be the more relevant skill for daily functioning. For this end, the MWT is the more suitable test. Subjects are usually seated in a chair in a dark room and are instructed to stay awake during a 20 - or 40-min trial, which is also repeated (normally 4 trials every $2 \mathrm{~h}$ ).

Apart from the MSLT and MWT, other objective assessments of wakefulness and sleepiness have been introduced. One class comprises performance tests, such as the Psychomotor Vigilance Task [33]. In these tests, subjects are requested to continuously perform an easy task, and it is recorded whether or not the subject is able to successfully carry out that task, as performance decrement can be used as an indicator of sleepiness. Another group of tests is again based on electrophysiological measures. Tests like the Karolinska Drowsiness Test [29] or the Alpha Attenuation Test [34] give an estimation of the current amount of wakefulness by comparing the EEG activity between eyes open and eyes closed conditions, as EEG activity changes distinctly in both conditions with increasing sleepiness. These tests can be repeated but are not useful to continuously measure vigilance fluctuations. One approach to overcome this limitation has been the Pupillographic Sleepiness Test [35], where the diameter of the pupil is continuously monitored, as this was found to be a marker for arousal. Pupil diameter is inversely related to sleepiness and its variability over time is used as indicator for changes in the amount of wakefulness. Still, EEG recordings provide the best temporal resolution and therefore remain the gold standard to objectively assess sleep stages and should also be the method of choice to assess wakefulness fluctuations.

As mentioned above, the wake state can be subdivided into several substages that can best be assessed using EEG recordings during wakefulness. According to original conceptions by Bente [8] and Roth [9], the following EEG vigilance stages can be observed during the transition from high alertness to relaxed wakefulness to drowsiness and finally sleep onset:

- Stage 0: desynchronized non-alpha EEG in the absence of slow horizontal eye movements; found during an activated state (e.g. mental effort)

- Stage A (with substages A1, A2, A3): EEG with dominant alpha activity corresponding to relaxed wakefulness, with decreasing vigilance, slight slowing of alpha activity and shift from occipital to more anterior cortices

- Stage B1: non-alpha EEG with low amplitude (similar spectral composition as stage 0 ) but with presence of slow horizontal eye movements; drowsiness

- Stage B2/3: non-alpha EEG with predominant theta/ delta activity, occasional occurrence of vertex waves; drowsiness and transition to sleep onset

- Stage C: commencing with occurrence of sleep spindles or K complexes; sleep onset

More recent studies on changes of EEG activity during the transition from active wakefulness to sleep onset endorse this classification [36-46].

Visual classification of vigilance stages in a resting EEG has been an arduous and time-consuming task comparable to the visual scoring of an overnight sleep poly- 
somnography. In the absence of explicit scoring rules, the problem of inter- and intrarater reliability is even more relevant than in sleep medicine where such rules have long been established [47, 48]. Furthermore, changes in wakefulness are not as uniform as the typical changes in sleep stages, as subjects go back and forth between vigilance stages with sometimes very short-lasting switches. Consequently, a segmentation of the resting EEG into 30 -second epochs as is the consensus in sleep medicine is not feasible for scoring vigilance changes in a resting EEG, where much shorter periods have to be considered. Therefore, the development of computer-assisted scoring algorithms has been essential for rejuvenating research interest in brain arousal regulation. Several algorithms have been put forward. In the following, we will focus on the Vigilance Algorithm Leipzig (VIGALL, see VIGALL manual at http://uni-leipzig.de/ vigall/).

VIGALL is an EEG- and electro-oculography-based algorithm which allows to objectively assess the level of EEG vigilance within multichannel EEG recordings, by automatically attributing one of the above-mentioned vigilance stages to EEG segments of preferable $1 \mathrm{~s}$ of duration [49-51]. The VIGALL algorithm takes into account different frequency bands and the cortical distribution of EEG activity using EEG source localization approaches (low-resolution electromagnetic tomography, LORETA [52, 53]). Since EEG activity is characterized by high intra-individual stability and large interindividual variability, VIGALL has adaptive features concerning individual alpha peaks and amplitude levels, by automatically detecting the individual alpha frequency and power from a representative epoch of alpha activity. Some of the parameters (e.g. upper and lower border of the alpha band) and decision criteria of the VIGALL (e.g. absolute alpha power necessary to classify an A stage) are then modified accordingly. Unfortunately, VIGALL is not applicable for certain EEGs, e.g. those showing non-alpha basic rhythms (e.g. low voltage type, beta type), major modifications due to drugs (e.g. anticholinergic drugs) or diseases (e.g. severe Alzheimer's disease) or EEGs from children under the age of 10 (or older in case of delayed maturation).

The very high temporal resolution allows investigations on how vigilance is regulated during the recording period, and this brain arousal or vigilance regulation shows considerable interindividual differences. During eyes-closed resting conditions of 15-20 min duration, most subjects show progressive declines to lower EEG vigilance stages (adaptive arousal regulation). However, while some subjects exhibit rapid declines within only a

Wakefulness and Brain Arousal

Regulation in Psychiatric Research few seconds (unstable arousal regulation), others steadily remain in stages of high vigilance (hyperstable arousal regulation). Naturally, this trait is modulated by the same individual and environmental factors that also affect sleep regulation such as accumulated sleep deficits, consumption of vigilance-affecting substances (e.g. caffeine, nicotine, drugs), effort or motivation to stay awake or fall asleep, and disease-related factors. Therefore, assessment of EEG vigilance has to adjust to certain standards. EEG recordings should be performed under comparable conditions: the EEG chamber should be well ventilated, steadily temperature controlled (approx. $22-24^{\circ} \mathrm{C}$ ), dimly lit and sound attenuated. The current degree of wakefulness should be assessed using questionnaires like the Stanford or Karolinska Sleepiness Scales, and sleep duration and quality in the preceding night should also be registered (by questionnaire or preferably objective assessments like actigraphy or polysomnography). Most important, however, would be that subjects are not to be awoken during the recording, even if they fall asleep, as would be the usual approach in so-called vigilance-controlled EEG recordings performed in quantitative EEG or event-related potential studies.

\section{Application of VIGALL}

The current VIGALL version (VIGALL 2.0; fig. 1) improves upon earlier versions of the algorithm which have been validated performing simultaneous EEG-functional MRI [50] as well as simultaneous EEG-PET studies [54] and by relating the vigilance stages to different behavioural and autonomic parameters [51, 55-57]. These basic research studies also imply clinical relevance given the importance of cognitive tests, MRI and PET in diagnostic procedures, where VIGALL might contribute to improve diagnostic accuracy by assessing arousal-induced error variance.

Regarding VIGALL's application in clinical groups and for treatment response prediction, several studies have been published recently: in major depression earlier EEG studies $[58,59]$ as well as more recent VIGALLbased studies $[60,61]$ revealed that depressed patients are characterized by a hyperstable arousal regulation, i.e. they show delayed or no decline to lower EEG vigilance stages under resting conditions. In contrast, $m a-$ nia was characterized by rapid EEG vigilance decline under resting conditions in former EEG case reports $[58,62,63]$, which was replicated in a more recent case report applying VIGALL [64]. In attention-deficit/hy- 


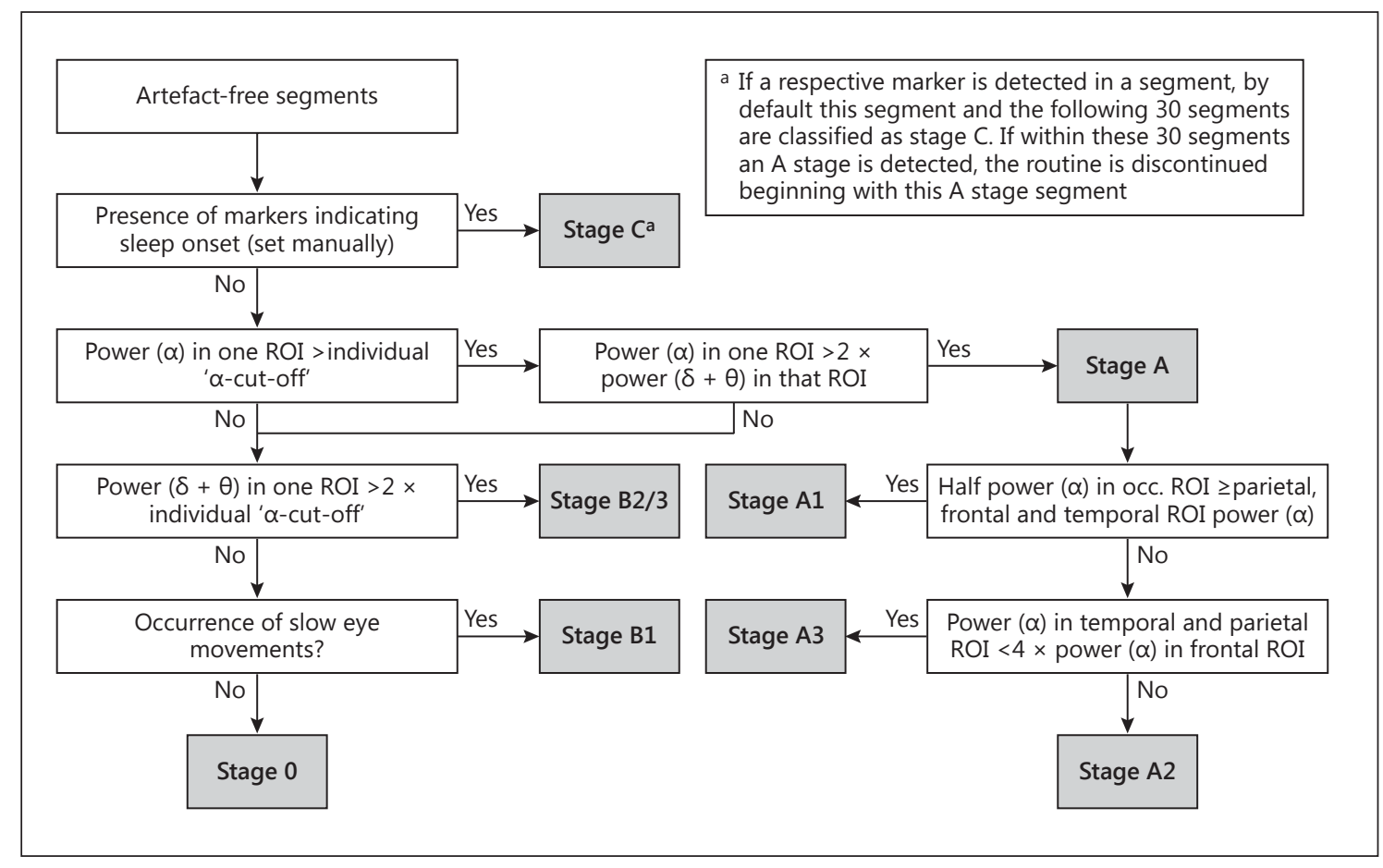

Fig. 1. Operational sequence and decision criteria of the VIGALL 2.0 algorithm. Classification of vigilance stages is based on power in 4 regions of interest (ROI; frontal, parietal, temporal and occipital lobes). For these regions of interest, alpha as well as delta + theta powers are calculated using LORETA. Beforehand VIGALL screens the EEG trace for a 10-second epoch with prominent alpha activity (default range $7.5-12.5 \mathrm{~Hz}$ ). For the respective epoch, the alpha centre of gravity frequency and mean power in the occipital region of interest are calculated. The alpha centre of gravity is then used to set the individual alpha range (alpha centre of gravity \pm $2 \mathrm{~Hz}$ ); the delta/theta range is fixed to $2-7 \mathrm{~Hz}$. Occipital alpha power is used to determine an individual alpha threshold which is then used as cut-off value in the classification of $A$ and B2/3 stages.

\section{The Vigilance Regulation Model of Affective Disorders and ADHD}

Building on the aforementioned empirical findings, the vigilance regulation model of affective disorders and ADHD has been proposed [71]. This model assumes that behaviour can create a more or less arousing environment in an autoregulatory manner in order to increase or reduce the brain arousal level. The hyperactive, impulsive, talkative and sensation-seeking behaviour in mania and ADHD is interpreted as an autoregulatory attempt to stabilize brain arousal by boosting stimulation from the environment or the behaviour itself (e.g. by fidgeting). In the context of normal behaviour, this phenomenon can be illustrated by overtired children, who often become agitated if they do not get to bed. This assumption that behaviour can influence brain arousal levels corresponds well with the secondary wake drive as proposed in the four-process model [20]. 
Specifically, for mania it is suggested that in vulnerable subjects an unstable brain arousal induces excessive autoregulatory behaviour in order to stabilize arousal, which overrides the physiological tendency to seek sleep, thereby exacerbating the sleep deficits and consequently the arousal instability. A vicious circle is initiated, which then contributes to mania. Whereas in mania this unstable arousal is triggered and built up state-like within the manic episode, in ADHD the unstable arousal is supposed to be a more stable trait. This unstable arousal trait may be acquired, genetic or resulting from chronic sleep disorders. On the other hand, the hyperstable arousal regulation in depression is thought to promote withdrawal and avoidance of social interactions, loud music and other external stimulations in order to downregulate the hyperarousal.

This arousal concept and the autoregulatory function of behaviour have already been suggested earlier $[8,58]$, and quite similar models have been proposed concerning personality traits such as sensation seeking [72] and extraversion [73]. These personality traits were also interpreted as autoregulatory behaviour in order to achieve an optimal level of arousal, and they were associated with affective disorders and ADHD [74, 75].

In the following, lines of evidence supporting the vigilance regulation model will shortly be drafted [for more details, see 71].

Concerning depression, a hyperstable arousal regulation is well in line with inner restlessness and tension and with heightened noradrenergic and hypothalamic-pituitary-adrenal activity [76, 77]. Most intriguingly, symptoms of anhedonia and inhibition have also been suggested to be a consequence of noradrenergic hyperactivity $[78,79]$. Furthermore, the tonic hyperarousal explains the pronounced insomnia in depression, including the increased sleep onset latency $[80,81]$. Several arousal-reducing interventions lead to improvement in depression, such as sleep deprivation which leads to a rapid and pronounced reduction of depressive symptomatology in more than half of the patients [82], whereas recovery sleep and short naps can result in prompt return of depressive symptomatology. Drowsiness is a highly frequent side effect of antidepressants [83-86], and all standard antidepressants, and also electroconvulsive therapy, reduce the firing rate of neurons in the noradrenergic locus coeruleus [87], which plays an essential role in arousal regulation [88-90]. In this context it is of interest that also other arousal-reducing drugs, such as scopolamine and ketamine, have demonstrated antidepressant effects $[91,92]$. In contrast, psychostimulants failed to show antidepressant effects in typical depression [71].

Wakefulness and Brain Arousal

Regulation in Psychiatric Research
The strongest triggers of mania and/or worsening of manic symptomatology are factors associated with sleep deficits or deprivation [93-101]. Also, antidepressants, which reduce brain arousal as mentioned above, can induce a switch into mania. According to some studies, this switch risk might be higher for antidepressants, which are particularly sedating [102-105]. In contrast, stabilization of the sleep-wake rhythm is an established part in behavioural therapies for bipolar disorder [106-108], and extended bed rest is used as an add-on in the treatment of acute mania [109-111]. Furthermore, case reports show acute antimanic effects of psychostimulants [reviewed in 112]. In case of rapid response to arousal-increasing drugs, clinical improvement usually goes along with increases in brain arousal $[64,113]$. Currently, a randomized placebo-controlled trial has been initiated testing acute antimanic properties of methylphenidate [114].

Concerning ADHD, lines of evidence are similar: studies applying skin conductance level, MSLT, MWT, quantitative EEG, VIGALL and Epworth Sleepiness Scale demonstrated that many ADHD patients are characterized by an unstable arousal regulation [66, 115-118]. Thus, the rapid therapeutic effects of stimulants in ADHD could be explained by their arousal-stabilizing properties. As in mania, all factors destabilizing arousal or inducing sleep deficits are reported to exaggerate ADHD, whereas interventions improving sleep quality and stabilizing arousal improve ADHD [118-121]. Furthermore, the unstable arousal regulation provides a simple explanation for the attention deficits in $\mathrm{ADHD}$, e.g. in continuous performance tasks [122], but also for the presentation specifiers according to DSM-5 (and the subtypes as their antecessors in the DSM-IV-TR). In the predominantly inattentive presentation, the deficits are explained by the unstable arousal regulation. In the combined presentation, with attention deficits and hyperactivity, additional autoregulatory aspects supervene with sensation seeking and hyperactivity as an attempt to stabilize arousal. The vigilance regulation model also explains the substantially lower prevalence rates for the predominantly hyperactiveimpulsive subtype whose general validity is in doubt [123, 124]: the suggested core pathogenetic factor (unstable brain arousal) leads to attention deficits, whereas hyperactivity does not represent a primary disorder per se, but an autoregulatory response, which may or may not be present.

At a first glance, the sleep onset insomnia reported for a subgroup of ADHD patients seems to be incompatible with the assumption of a chronic unstable arousal regulation in this condition. However, there are several reasons 
why sleep onset insomnia might occur despite an unstable arousal regulation. First, according to the vigilance regulation model, compensatory stimulation and sensation-seeking behaviour can result in inability or reluctance to settle into sleep [125]. Secondly, following the two-process model of sleep, a circadian phase delay (process C) can inhibit sleep onset, although sleep pressure is high enough (process S): studies have shown that children and adults with ADHD have a significantly delayed sleep onset, caused by a delayed melatonin onset (process C) [126-128]. As a result, going to bed too late will further increase the unstable arousal regulation. Finally, in treated patients, it is also possible that taking a stimulant dose too close to bedtime will result in insomnia as side effect, although stimulants might also improve sleep in ADHD $[125,129]$.

\section{Conclusion}

Arousal regulation is a fundamental trait and potential endophenotype [130,131], which, according to the proposed vigilance regulation model, not only modulates, but also triggers normal and abnormal behaviour. The newly developed and validated EEG-based algorithm VIGALL promises progress in research on confounding, modulating and moderating roles of arousal on behaviour. Available evidence points to an important role of arousal dysregulation in the aetiopathology of affective disorders and ADHD. Assessment of arousal regulation could help to define more homogeneous subgroups in these highly heterogeneous phenotypical categories, which might in turn improve drug development, differential diagnoses and aetiological research. According to the vigilance regulation model, stimulating drugs should be helpful in those ADHD and manic patients, who show the characteristic unstable arousal regulation. In depression, also for subgroups of patients (such as patients with atypical or secondary depression, or some bipolar patients), an unstable arousal regulation is hypothesized [71], whereas in the majority of patients with major depression hyperstable arousal seems to be characteristic. Currently, studies are under way, which will give first evidence whether VIGALL is able to predict the treatment response to selective serotonin reuptake inhibitors in depression and to stimulants in ADHD and mania, which might then contribute to a more personalized treatment.

\section{References}

1 Wichniak A, Wierzbicka A, Jernajczyk W: Sleep and antidepressant treatment. Curr Pharm Des 2012;18:5802-5817.

$\checkmark 2$ Nutt D, Wilson S, Paterson L: Sleep disorders as core symptoms of depression. Dialogues Clin Neurosci 2008;10:329-336.

3 Wehr TA: Sleep loss: a preventable cause of mania and other excited states. J Clin Psychiatry 1989;50(suppl):8-16; discussion $45-$ 47.

4 Bauer M, Grof P, Rasgon N, Bschor T, Glenn $\mathrm{T}$, Whybrow PC: Temporal relation between sleep and mood in patients with bipolar disorder. Bipolar Disord 2006;8:160-167.

5 Giedke H, Schwarzler F: Therapeutic use of sleep deprivation in depression. Sleep Med Rev 2002;6:361-377.

6 Dirksen SR, Epstein DR: Efficacy of an insomnia intervention on fatigue, mood and quality of life in breast cancer survivors. J Adv Nurs 2008;61:664-675.

7 Manber R, Edinger JD, Gress JL, San PedroSalcedo MG, Kuo TF, Kalista T: Cognitive behavioral therapy for insomnia enhances depression outcome in patients with comorbid major depressive disorder and insomnia Sleep 2008;31:489-495.
8 Bente D: Vigilanz, dissoziative Vigilanzverschiebung und Insuffizienz des Vigilitätstonus; in Kranz H, Heinrich K (eds): Begleitwirkungen und Misserfolge der psychiatrischen Pharmakotherapie. Stuttgart, Thieme, 1964, pp 13-28.

9 Roth B: The clinical and theoretical importance of EEG rhythms corresponding to states of lowered vigilance. Electroencephalogr Clin Neurophysiol 1961;13:395-399.

10 Pfaff D, Ribeiro A, Matthews J, Kow LM: Concepts and mechanisms of generalized central nervous system arousal. Ann NY Acad Sci 2008;1129:11-25.

11 Oken BS, Salinsky MC, Elsas SM: Vigilance, alertness, or sustained attention: physiological basis and measurement. Clin Neurophysiol 2006;117:1885-1901.

$12 \mathrm{Head} \mathrm{H}$ : The conception of nervous and mental energy. II. Vigilance: a physiological state of the nervous system. Br J Psychol 1923;14: 126-147.

13 Cluydts R, De Valck E, Verstraeten E, Theys P: Daytime sleepiness and its evaluation. Sleep Med Rev 2002;6:83-96.

14 Borbely AA: A two process model of sleep regulation. Hum Neurobiol 1982;1:195-204.
15 Daan S, Beersma DG, Borbely AA: Timing of human sleep: recovery process gated by a circadian pacemaker. Am J Physiol 1984; 246:R161-R183.

16 Akerstedt T, Folkard S: Predicting duration of sleep from the three process model of regulation of alertness. Occup Environ Med 1996; 53:136-141.

17 Akerstedt T, Folkard S: The three-process model of alertness and its extension to performance, sleep latency, and sleep length. Chronobiol Int 1997;14:115-123.

18 Akerstedt T, Folkhard SA: A model of human sleepiness; in Horne JA (ed): Sleep '90. Bochum, Pontenagel Press, 1990, pp 310-313.

19 Achermann P: The two-process model of sleep regulation revisited. Aviat Space Environ Med 2004;75:A37-A43

20 Johns M: Rethinking the assessment of sleepiness. Sleep Med Rev 1998;2:3-15.

21 Brown RE, Basheer R, McKenna JT, Strecker RE, McCarley RW: Control of sleep and wakefulness. Physiol Rev 2012;92:1087-1187.

22 Richter C, Woods IG, Schier AF: Neuropeptidergic control of sleep and wakefulness. Annu Rev Neurosci 2014;37:503-531.

23 Rosenwasser AM: Functional neuroanatomy of sleep and circadian rhythms. Brain Res Rev 2009;61:281-306. 
-24 Saper CB, Fuller PM, Pedersen NP, Lu J, Scammell TE: Sleep state switching. Neuron 2010;68:1023-1042.

25 Porkka-Heiskanen T, Strecker RE, Thakkar M, Bjorkum AA, Greene RW, McCarley RW: Adenosine: a mediator of the sleep-inducing effects of prolonged wakefulness. Science 1997;276:1265-1268.

26 Mathis J, Hess CW: Sleepiness and vigilance tests. Swiss Med Wkly 2009;139:214-219.

27 Johns MW: A new method for measuring daytime sleepiness: the Epworth Sleepiness Scale. Sleep 1991;14:540-545.

28 Hoddes E, Dement W, Zarcone V: The development and use of the Stanford Sleepiness Scale (SSS). Psychophysiology 1972;9:150151.

29 Akerstedt T, Gillberg M: Subjective and objective sleepiness in the active individual. Int J Neurosci 1990;52:29-37.

30 Carskadon MA, Dement WC, Mitler MM, Roth T, Westbrook PR, Keenan S: Guidelines for the Multiple Sleep Latency Test (MSLT): a standard measure of sleepiness. Sleep 1986;9: 519-524.

- 31 Mitler MM, Gujavarty KS, Browman CP: Maintenance of Wakefulness Test: a polysomnographic technique for evaluation treatment efficacy in patients with excessive somnolence. Electroencephalogr Clin Neurophysiol 1982;53:658-661.

32 Sangal RB, Thomas L, Mitler MM: Maintenance of wakefulness test and multiple sleep latency test. Measurement of different abilities in patients with sleep disorders. Chest 1992;101:898-902.

33 Dinges DF, Powell JW: Microcomputer analyses of performance on a portable, simple visual RT task during sustained operations. Behav Res Methods Instr Comput 1985;17:652655.

-34 Stampi C, Stone P, Michimori A: A new quantitative method for assessing sleepiness. Work Stress 1995;9:368-376.

35 Wilhelm B, Giedke H, Ludtke H, Bittner E, Hofmann A, Wilhelm H: Daytime variations in central nervous system activation measured by a pupillographic sleepiness test. J Sleep Res 2001;10:1-7.

- 36 Benca RM, Obermeyer WH, Larson CL, Yun B, Dolski I, Kleist KD, Weber SM, Davidson RJ: EEG alpha power and alpha power asymmetry in sleep and wakefulness. Psychophysiology 1999;36:430-436.

37 Cantero JL, Atienza M, Salas RM: Human alpha oscillations in wakefulness, drowsiness period, and rem sleep: different electroencephalographic phenomena within the alpha band. Neurophysiol Clin 2002;32:54-71.

-38 Corsi-Cabrera M, Guevara MA, Del Rio-Portilla Y, Arce C, Villanueva-Hernandez Y: EEG bands during wakefulness, slow-wave and paradoxical sleep as a result of principal component analysis in man. Sleep 2000;23:738744.

39 De Gennaro L, Ferrara M: Sleep spindles: an overview. Sleep Med Rev 2003;7:423-440.
40 De Gennaro L, Ferrara M, Curcio G, Cristiani R: Antero-posterior EEG changes during the wakefulness-sleep transition. Clin Neurophysiol 2001;112:1901-1911.

41 De Gennaro L, Vecchio F, Ferrara M, Curcio G, Rossini PM, Babiloni C: Changes in frontoposterior functional coupling at sleep onset in humans. J Sleep Res 2004;13:209-217.

42 Kaida K, Takahashi M, Akerstedt T, Nakata A, Otsuka Y, Haratani T, Fukasawa K: Validation of the Karolinska Sleepiness Scale against performance and EEG variables. Clin Neurophysiol 2006;117:1574-1581.

43 Marzano C, Fratello F, Moroni F, Pellicciari MC, Curcio G, Ferrara M, Ferlazzo F, De Gennaro L: Slow eye movements and subjective estimates of sleepiness predict EEG power changes during sleep deprivation. Sleep 2007;30:610-616.

-44 Tsuno N, Shigeta M, Hyoki K, Kinoshita T, Ushijima S, Faber PL, Lehmann D: Spatial organization of EEG activity from alertness to sleep stage 2 in old and younger subjects. J Sleep Res 2002;11:43-51.

45 De Gennaro L, Ferrara M, Bertini M: The boundary between wakefulness and sleep: quantitative electroencephalographic changes during the sleep onset period. Neuroscience 2001;107:1-11.

46 Strijkstra AM, Beersma DG, Drayer B, Halbesma N, Daan S: Subjective sleepiness correlates negatively with global alpha $(8-12 \mathrm{~Hz})$ and positively with central frontal theta (4-8 $\mathrm{Hz}$ ) frequencies in the human resting awake electroencephalogram. Neurosci Lett 2003; 340:17-20.

47 Iber C, Ancoli-Israel S, Chessonn A, Quan SF: The AASM Manual for the Scoring of Sleep and Associated Events: Rules, Terminology and Technical Specifications, ed 1. Westchester, American Academy of Sleep Medicine, 2007.

48 Rechtschaffen A, Kales A: A Manual of Standardized Terminology Technics and Scoring Systems for Sleep of Human Subjects. Washington, US Government Printing Office, 1968.

49 Hegerl U, Stein M, Mulert C, Mergl R, Olbrich S, Dichgans E, Rujescu D, Pogarell O: EEGvigilance differences between patients with borderline personality disorder, patients with obsessive-compulsive disorder and healthy controls. Eur Arch Psychiatry Clin Neurosci 2008;258:137-143.

50 Olbrich S, Mulert C, Karch S, Trenner M, Leicht G, Pogarell O, Hegerl U: EEG-vigilance and BOLD effect during simultaneous EEG/ fMRI measurement. Neuroimage 2009; 45 : 319-332.

51 Olbrich S, Sander C, Matschinger H, Mergl R, Trenner M, Schoenknecht P, Hegerl U: Brain and body: associations between EEG-vigilance and the autonomous nervous system activity during rest. J Psychophysiol 2011;25: 190-200.
52 Pascual-Marqui RD, Esslen M, Kochi K, Lehmann D: Functional imaging with lowresolution brain electromagnetic tomography (LORETA): a review. Methods Find Exp Clin Pharmacol 2002;24(suppl C):91-95.

53 Pascual-Marqui RD, Michel CM, Lehmann D: Low resolution electromagnetic tomography: a new method for localizing electrical activity in the brain. Int J Psychophysiol 1994; 18:49-65.

54 Guenther T, Schonknecht P, Becker G, Olbrich S, Sander C, Hesse S, Meyer PM, Luthardt J, Hegerl U, Sabri O: Impact of EEG-vigilance on brain glucose uptake measured with [(18) F]FDG and PET in patients with depressive episode or mild cognitive impairment. Neuroimage 2011;56:93-101.

55 Minkwitz J, Trenner MU, Sander C, Olbrich S, Sheldrick AJ, Hegerl U, Himmerich $\mathrm{H}$ : Time perception at different EEG-vigilance levels. Behav Brain Funct 2012;8:50.

56 Minkwitz J, Trenner MU, Sander C, Olbrich S, Sheldrick AJ, Schoenknecht P, Hegerl U, Himmerich H: Prestimulus vigilance predicts response speed in an easy visual discrimination task. Behav Brain Funct 2011;7:31.

-57 Bekhtereva V, Sander C, Forschack N, Olbrich S, Hegerl U, Muller MM: Effects of EEGvigilance regulation patterns on early perceptual processes in human visual cortex. Clin Neurophysiol 2014;125:98-107.

58 Ulrich G: Psychiatrische Elektroenzephalographie. Jena, Fischer, 1994.

59 Ulrich G, Fuerstenberg U: Quantitative assessment of dynamic electroencephalogram (EEG) organization as a tool for subtyping depressive syndromes. Eur Psychiatry 1999;14:217-229.

60 Hegerl U, Wilk K, Olbrich S, Schoenknecht P, Sander C: Hyperstable regulation of vigilance in patients with major depressive disorder. World J Biol Psychiatry 2012;13:436-446.

61 Olbrich S, Sander C, Minkwitz J, Chittka T, Mergl R, Hegerl U, Himmerich H: EEG vigilance regulation patterns and their discriminative power to separate patients with major depression from healthy controls. Neuropsychobiology 2012;65:188-194.

62 Small JG, Milstein V, Malloy FW, Medlock $\mathrm{CE}$, Klapper MH: Clinical and quantitative EEG studies of mania. J Affect Disord 1999; 53:217-224.

63 Van Sweden B: Disturbed vigilance in mania. Biol Psychiatry 1986;21:311-313.

64 Schoenknecht P, Olbrich S, Sander C, Spindler P, Hegerl U: Treatment of acute mania with modafinil monotherapy. Biol Psychiatry 2010;67:e55-e57.

65 Hegerl U, Himmerich H, Engmann B, Hensch T: Mania and attention-deficit/hyperactivity disorder: common symptomatology, common pathophysiology and common treatment? Curr Opin Psychiatry 2010;23:1-7.

66 Geissler J, Romanos M, Hegerl U, Hensch T: Hyperactivity and sensation seeking as autoregulatory attempts to stabilize brain arousal in ADHD and mania? Atten Defic Hyperact Disord 2014;6:159-173.
Wakefulness and Brain Arousal

Regulation in Psychiatric Research
Neuropsychobiology 2015;72:195-205 DOI: $10.1159 / 000439384$ 
67 Sander C, Arns M, Olbrich S, Hegerl U: EEGvigilance and response to stimulants in paediatric patients with attention deficit/hyperactivity disorder. Clin Neurophysiol 2010;121: 1511-1518.

68 Olbrich S, Olbrich H, Jahn I, Sander C, Adamaszek M, Hegerl U, Reque F, Stengler K: EEG-vigilance regulation during the resting state in obsessive-compulsive disorder. Clin Neurophysiol 2013;124:497-502.

-69 Hegerl U, Lam RW, Malhi GS, McIntyre RS, Demyttenaere K, Mergl R, Gorwood P: Conceptualising the neurobiology of fatigue. Aust NZ J Psychiatry 2013;47:312-316.

-70 Olbrich S, Sander C, Jahn I, Eplinius F, Claus S, Mergl R, Schonknecht P, Hegerl U: Unstable EEG-vigilance in patients with cancer-related fatigue (CRF) in comparison to healthy controls. World J Biol Psychiatry 2012;13 146-152.

71 Hegerl U, Hensch T: The vigilance regulation model of affective disorders and ADHD. Neurosci Biobehav Rev 2014;44:45-57.

72 Zuckerman M: Sensation-Seeking: Beyond the Optimal Level of Arousal. Hillsdale, Erlbaum, 1979.

73 Eysenck HJ: Biological dimensions of personality; in Pervin LA (ed): Handbook of Personality: Theory and Research. New York, Guilford Press, 1990, pp 244-276.

-74 Hensch T, Herold U, Brocke B: An electrophysiological endophenotype of hypomanic and hyperthymic personality. J Affect Disord 2007;101:13-26.

75 White JD: Personality, temperament and ADHD: a review of the literature. Pers Individ Diff 1999;27:589-598.

76 Pariante CM, Lightman SL: The HPA axis in major depression: classical theories and new developments. Trends Neurosci 2008;31: 464-468.

77 Wong ML, Kling MA, Munson PJ, Listwak S, Licinio J, Prolo P, Karp B, McCutcheon IE, Geracioti TD Jr, DeBellis MD, Rice KC, Goldstein DS, Veldhuis JD, Chrousos GP, Oldfield EH, McCann SM, Gold PW: Pronounced and sustained central hypernoradrenergic function in major depression with melancholic features: relation to hypercortisolism and corticotropin-releasing hormone. Proc Natl Acad Sci USA 2000;97:325-330.

-78 Stone EA, Lin Y, Sarfraz Y, Quartermain D: The role of the central noradrenergic system in behavioral inhibition. Brain Res Rev 2011; 67:193-208.

79 West CH, Weiss JM: Effects of chronic antidepressant drug administration and electroconvulsive shock on activity of dopaminergic neurons in the ventral tegmentum. Int J Neuropsychopharmacol 2011;14:201-210.

80 Armitage R: Sleep and circadian rhythms in mood disorders. Acta Psychiatr Scand 2007; 115:104-115.

81 Tsuno N, Besset A, Ritchie K: Sleep and depression. J Clin Psychiatry 2005;66:12541269.
82 Benedetti F, Colombo C: Sleep deprivation in mood disorders. Neuropsychobiology 2011; 64:141-151

83 Bull SA, Hunkeler EM, Lee JY, Rowland CR, Williamson TE, Schwab JR, Hurt SW: Discontinuing or switching selective serotoninreuptake inhibitors. Ann Pharmacother 2002; 36:578-584.

84 Cascade E, Kalali AH, Kennedy SH: Realworld data on SSRI antidepressant side effects. Psychiatry (Edgmont) 2009;6:16-18.

85 Fava M, Graves LM, Benazzi F, Scalia MJ, Iosifescu DV, Alpert JE, Papakostas GI: A cross-sectional study of the prevalence of cognitive and physical symptoms during longterm antidepressant treatment. J Clin Psychiatry 2006;67:1754-1759.

86 Papakostas GI: Tolerability of modern antidepressants. J Clin Psychiatry 2008;69(suppl E1):8-13.

87 West $\mathrm{CH}$, Ritchie JC, Boss-Williams KA, Weiss JM: Antidepressant drugs with differing pharmacological actions decrease activity of locus coeruleus neurons. Int J Neuropsychopharmacol 2009;12:627-641.

88 Berridge CW: Noradrenergic modulation of arousal. Brain Res Rev 2008;58:1-17.

89 Berridge CW, Waterhouse BD: The locus coeruleus-noradrenergic system: modulation of behavioral state and state-dependent cognitive processes. Brain Res Brain Res Rev 2003; 42:33-84.

90 Valentino RJ, Van Bockstaele E: Convergent regulation of locus coeruleus activity as an adaptive response to stress. Eur J Pharmacol 2008;583:194-203.

-91 Drevets WC, Furey ML: Replication of scopolamine's antidepressant efficacy in major depressive disorder: a randomized, placebocontrolled clinical trial. Biol Psychiatry 2010; 67:432-438.

92 Coyle CM, Laws KR: The use of ketamine as an antidepressant: a systematic review and meta-analysis. Hum Psychopharmacol 2015; 30:152-163.

93 Barbini B, Bertelli S, Colombo C, Smeraldi E: Sleep loss, a possible factor in augmenting manic episode. Psychiatry Res 1996;65:121125 .

94 Colombo C, Benedetti F, Barbini B, Campori E, Smeraldi E: Rate of switch from depression into mania after therapeutic sleep deprivation in bipolar depression. Psychiatry Res 1999;86: 267-270.

95 Harvey AG: Sleep and circadian rhythms in bipolar disorder: seeking synchrony, harmony, and regulation. Am J Psychiatry 2008;165: 820-829.

96 Plante DT, Winkelman JW: Sleep disturbance in bipolar disorder: therapeutic implications. Am J Psychiatry 2008;165:830-843.

97 Wehr TA: Sleep-loss as a possible mediator of diverse causes of mania. Br J Psychiatry 1991; 159:576-578.

98 Wehr TA: Improvement of depression and triggering of mania by sleep deprivation. JAMA 1992;267:548-551.
\$9 Wu JC, Bunney WE: The biological basis of an antidepressant response to sleep deprivation and relapse: review and hypothesis. Am J Psychiatry 1990;147:14-21.

100 Gessa GL, Pani L, Fadda P, Fratta W: Sleep deprivation in the rat: an animal model of mania. Eur Neuropsychopharmacol 1995; 5(suppl):89-93.

101 Kasper S, Wehr TA: The role of sleep and wakefulness in the genesis of depression and mania. Encephale 1992;18:45-50.

102 Gijsman HJ, Geddes JR, Rendell JM, Nolen WA, Goodwin GM: Antidepressants for bipolar depression: a systematic review of randomized, controlled trials. Am J Psychiatry 2004;161:1537-1547.

103 Jabeen S, Fisher CJ: Trazodone-induced transient hypomanic symptoms and their management. Br J Psychiatry 1991;158:275278.

104 Peet M: Induction of mania with selective serotonin re-uptake inhibitors and tricyclic antidepressants. Br J Psychiatry 1994;164: 549-550.

105 Terao T: Comparison of manic switch onset during fluoxetine and trazodone treatment. Biol Psychiatry 1993;33:477-478.

106 Frank E, Kupfer DJ, Thase ME, Mallinger AG, Swartz HA, Fagiolini AM, Grochocinski V, Houck P, Scott J, Thompson W, Monk T: Two-year outcomes for interpersonal and social rhythm therapy in individuals with bipolar I disorder. Arch Gen Psychiatry 2005; 62:996-1004.

107 Leibenluft E, Suppes T: Treating bipolar illness: focus on treatment algorithms and management of the sleep-wake cycle. Am J Psychiatry 1999;156:1976-1981.

108 Riemann D, Voderholzer U, Berger M: Sleep and sleep-wake manipulations in bipolar de$\begin{array}{ll}\text { pression. Neuropsychobiology 2002; } 45 & 0\end{array}$ (suppl 1):7-12.

109 Barbini B, Benedetti F, Colombo C, Dotoli D, Bernasconi A, Cigala-Fulgosi M, Florita M, Smeraldi E: Dark therapy for mania: a pilot study. Bipolar Disord 2005;7:98-101.

110 Nowlin-Finch NL, Altshuler LL, Szuba MP, Mintz J: Rapid resolution of first episodes of mania: sleep related? J Clin Psychiatry 1994; 55:26-29.

-111 Wehr TA, Turner EH, Shimada JM, Lowe $\mathrm{CH}$, Barker C, Leibenluft E: Treatment of rapidly cycling bipolar patient by using extended bed rest and darkness to stabilize the timing and duration of sleep. Biol Psychiatry 1998;43:822-828.

112 Hegerl U, Sander C, Olbrich S, Schoenknecht P: Are psychostimulants a treatment option in mania? Pharmacopsychiatry 2009; 42:169-174.

113 Bschor T, Muller-Oerlinghausen B, Ulrich G: Decreased level of EEG-vigilance in acute mania as a possible predictor for a rapid effect of methylphenidate: a case study. Clin Electroencephalogr 2001;32:36-39. 
114 Kluge M, Hegerl U, Sander C, Dietzel J, Mergl R, Bitter I, Demyttenaere K, Gusmao R, Gonzalez-Pinto A, Perez-Sola V, Vieta E, Juckel G, Zimmermann US, Bauer M, Sienaert P, Quintao S, Edel MA, Bolyos C, Ayuso-Mateos JL, Lopez-Garcia P: Methylphenidate in Mania Project (MEMAP): study protocol of an international randomised double-blind placebo-controlled study on the initial treatment of acute mania with methylphenidate. BMC Psychiatry 2013;13: 71.

115 Arns M, Kenemans JL: Neurofeedback in ADHD and insomnia: vigilance stabilization through sleep spindles and circadian networks. Neurosci Biobehav Rev 2014;44:183194.

-116 Bioulac S, Micoulaud-Franchi JA, Philip P: Excessive daytime sleepiness in patients with ADHD - diagnostic and management strategies. Curr Psychiatry Rep 2015;17: 608.

117 Cortese S, Faraone SV, Konofal E, Lecendreux M: Sleep in children with attentiondeficit/hyperactivity disorder: meta-analysis of subjective and objective studies. J Am Acad Child Adolesc Psychiatry 2009;48: 894-908.

118 Yoon SY, Jain U, Shapiro C: Sleep in attention-deficit/hyperactivity disorder in children and adults: past, present, and future. Sleep Med Rev 2012;16:371-388.
119 Fallone G, Acebo C, Seifer R, Carskadon MA: Experimental restriction of sleep opportunity in children: effects on teacher ratings. Sleep 2005;28:1561-1567.

120 Gruber R, Wiebe S, Montecalvo L, Brunetti B, Amsel R, Carrier J: Impact of sleep restriction on neurobehavioral functioning of children with attention deficit hyperactivity disorder. Sleep 2011;34:315-323.

121 Gruber R, Xi T, Frenette S, Robert M, Vannasinh P, Carrier J: Sleep disturbances in prepubertal children with attention deficit hyperactivity disorder: a home polysomnography study. Sleep 2009;32:343-350.

122 Nichols SL, Waschbusch DA: A review of the validity of laboratory cognitive tasks used to assess symptoms of ADHD. Child Psychiatry Hum Dev 2004;34:297-315.

123 Hurtig T, Ebeling H, Taanila A, Miettunen J, Smalley SL, McGough JJ, Loo SK, Jarvelin MR, Moilanen IK: ADHD symptoms and subtypes: relationship between childhood and adolescent symptoms. J Am Acad Child Adolesc Psychiatry 2007;46:1605-1613.

124 Willcutt EG, Nigg JT, Pennington BF, Solanto MV, Rohde LA, Tannock R, Loo SK, Carlson CL, McBurnett K, Lahey BB: Validity of DSM-IV attention deficit/hyperactivity disorder symptom dimensions and subtypes. J Abnorm Psychol 2012;121:9911010.

125 Brown TE, McMullen WJ Jr: Attention deficit disorders and sleep/arousal disturbance. Ann NY Acad Sci 2001;931:271-286.
26 Arns M, Feddema I, Kenemans JL: Differential effects of theta/beta and SMR neurofeedback in ADHD on sleep onset latency. Front Hum Neurosci 2014;8:1019.

127 Van der Heijden KB, Smits MG, Van Someren EJ, Gunning WB: Idiopathic chronic sleep onset insomnia in attention-deficit/hyperactivity disorder: a circadian rhythm sleep disorder. Chronobiol Int 2005;22:559570.

128 Van Veen MM, Kooij JJ, Boonstra AM, Gordijn MC, Van Someren EJ: Delayed circadian rhythm in adults with attention-deficit/hyperactivity disorder and chronic sleep-onset insomnia. Biol Psychiatry 2010, 67:1091-1096.

129 Sobanski E, Schredl M, Kettler N, Alm B: Sleep in adults with attention deficit hyperactivity disorder (ADHD) before and during treatment with methylphenidate: a controlled polysomnographic study. Sleep 2008; 31:375-381.

130 Huang J, Sander C, Jawinski P, Ulke C, Spada J, Hegerl U, Hensch T: Test-retest reliability of brain arousal regulation as assessed with VIGALL 2.0. Neuropsychiatric Electrophysiology 2015; 1:13.

131 Jawinski P, Sander C, Mauche N, Spada J, Huang J, Schmidt A, Häntzsch M, Burkhardt R, Scholz M, Hegerl U, Hensch T: Brain arousal regulation in carriers of bipolar disorder risk alleles. Neuropsychobiology (in press), DOI: 10.1159/000437438. 